\title{
Comparison of WF \& Tubular Links on the Eccentrically Brace Frame System due to Cyclic Loads
}

\author{
Budi Suswanto $^{\#}$, Aniendhita Rizki Amalia*, Endah Wahyuni", Najibullah Al Farisy ${ }^{\#}$ \\ \#Department of Civil Engineering, Institut Teknologi Sepuluh Nopember, Surabaya, 60111, Indonesia \\ E-mail: aniendhita.ra@gmail.com
}

\begin{abstract}
Eccentrically Brace Frame system develops its ductility using link inelasticity. Therefore, the strength of the structure in resisting the lateral force is highly dependent on the link and some types of link that are commonly used. Furthermore, it needs to compare the behavior of two section frames that most commonly used as a link in EBF system building; they are WF section and tubular section. In addition to the cross-sectional factors, deformation of the link is also highly dependent on the length of the link, hence the test will also be done on three different type of link lengths, they are short links, intermediate links, and long links, that are according to the classification of link lengths defined in AISC Seismic Provision. Before starting the analysis, a literature study has been reviewed to learn more about the behavior of a link under cyclic load. The numerical analysis has been done to find the strength of the link and modeling with the Finite Element Analysis (FEA) using ABAQUS. After all analysis and the calculation are completed, the results will appear in three-dimensional modeling form, Displacement versus Force diagrams and the stress-strain curves to show the ductility of all specimens. The result of the study showed that in short links, both WF link and tubular link achieve nominal shear force is equal to $V_{p}$ plastic shear force with values $390 \mathrm{kN}$ for tubular section and $437 \mathrm{kN}$ for WF section, and the value of shear force to the classification of the short link is very dependent on the body cross-sectional area. Tubular link's body with an area of $89 \%$ of the WF link total weight generates shear forces $89 \%$ of the shear force from WF link because the formulation of the plastic shear force $V_{p}$ is highly dependent on factors of body cross-sectional area $\left(A_{w}\right)$. According to the research result, it shows that for both WF and tubular link cannot reach nominal shear force when the length of the link over the requirement of the shear link.
\end{abstract}

Keywords - tubular link, WF link, EBF, cyclic loads tubular.

\section{INTRODUCTION}

Eccentrically Braced Frame (EBF) structural system is one of the types of earthquake resistance building that commonly uses around the world, that is a system that limits the inelastic behavior to only the link beam that lies between two eccentric braces, while the outer beam, column, and diagonal braces remain elastic during the seismic loading. Therefore, Eccentrically Braced Frame (EBF) systems can meet high ductility levels such as Moment Resisting Frame (MRF), and can also provide high elastic stiffness levels such as Concentrically Braced Frame (CBF) [5].

The link is a part of EBF system that needs particular attention because when the lateral force being loaded, the highest value of internal force such as moment and shear will happen at the link. There are two types of link that are commonly used; they are WF link and tubular link. Berman and Bruneau [7] [8] wrote that tubular link with a different cross-section from its flange and body could reach rotation value until $0.15 \mathrm{rad}$. That tubular link value is two times more than IWF section (that is only $0,08 \mathrm{rad}$ ), as written in AISC.
The links in the EBF are formed from offsets at the braces connections on beam or braces adjacent to the columns so that during the seismic load the link becomes active and yielding [11]. Alternatively, in other words, the link acts as a ductile fuse during an earthquake loading so that the link will undergo an inelastic rotation while the other components of EBF remain elastic [12].

There are three possible link beam criteria in the EBF structural system that are; short links, intermediate links and long links [13]. This criterion are determined by the normalization of link length with the ratio between plastic moment capacity $\left(M_{p}\right)$ and plastic shear capacity $\left(V_{p}\right)$. Length of the link is classified into three types by AISC [1], as its relationship graph of plastic rotation with its length.

That three types are: (1) Short link, with the requirement: $\mathrm{Mp} / \mathrm{Vp} \leq 1.6$; (2). Intermediate link, with requirement: $1.6<$ $\mathrm{Mp} / \mathrm{Vp} \leq 2.6$; (3) Long link, with requirement: $2.6<\mathrm{Mp} / \mathrm{Vp}$. Okazaki [10] suggest the cyclic load that is given have to represent the real earthquake load, because of number and value of cyclic load given each period will very affect to the value of reached plastic rotation. As a result, expected ductility value and stress to be reached could approximately 
reach the real value that will happen when the EBF building receives real earthquake load.

A study conducted by Musmar [9] showed that the EBF system with the shear link was more stable and showed more ductility than the moment-shear link. This is due to the constant internal shear force along the links, and the yielding on the web takes place along the web plane of the link. Numerical analysis carried out by Hashemi [6] to the EBF frame with long link criteria indicates that yielding on the link beam is because of the bending force. The energy absorption on the flange is less than the shear link condition due to the occurrence of premature buckling on the flange part of the link beam. To reduce this, it can be controlled by placing web stiffeners on the link beam although it is not very efficient because of the influence of torque. Yurisman et al. [14] and Budiono et al. [4] perform experimental testing and numerical analysis of short-link beam elements (shear links) and long links (bending links) using diagonal web diagonals (diagonal web stiffeners). Suswanto [2] said Link with classification as a short link, will have a higher ductility than the long link. EBF concept design makes sure the link as the firstly fail and the element of the other remain elastic.

\section{MATERIAL AND METHOD}

\section{A. General}

Firstly, literature studies have been done before the research started. The research started with define the specimen to be modeled and then be analyzed. Each model has different section and categories. There was 7 type of models to be analyzed with, as seen below:

1. Tubular link 150.150.16.18 - Short link $(\mathrm{e}=46 \mathrm{~cm})$.

2. Tubular link 150.150.16.18 - Intermediate link $(e=75$ $\mathrm{cm})$.

3. Tubular link 150.150.16.18 - Long link $(\mathrm{e}=175 \mathrm{~cm})$.

4. WF 200.200.12.12 - Short link $(\mathrm{e}=46 \mathrm{~cm})$.

5. WF 200.200.12.12 - Intermediate link $(\mathrm{e}=105 \mathrm{~cm})$.

6. WF 200.150.6.9 - Intermediate link $(\mathrm{e}=150 \mathrm{~cm})$.

7. WF 200.150.6.9 - Long link $(e=175 \mathrm{~cm})$.

In analysis process, each model geometry and type of the material have to be defined first like the following type. Then from study literature result, displacement load of each link was defined as seen in AISC 2010, chapter 4c "Cycle test for Qualification - Loading Sequence for the link to column connection." The defined displacement load then used to chosen steps and cyclic load numbers as seen in Table 1.

After that, the cyclic displacement loading process started using Finite Element Analysis software. The output of that process was created to be table and graphs.

\section{B. Structural Modelling}

Before modeling link structure using Finite Element Analysis software, specimen dimension has to be checked first, from the tendency of lateral and local buckling. As a result, each section that chosen to be modelled were a short section. Displacement control load was chosen to be loading input. The value that is used as a result of tan of radian that is multiplied with the length of the link, as labeled in Table 1.

TABLE I

DisPlaCEMENT VALUE OF EACH MODEL TyPE

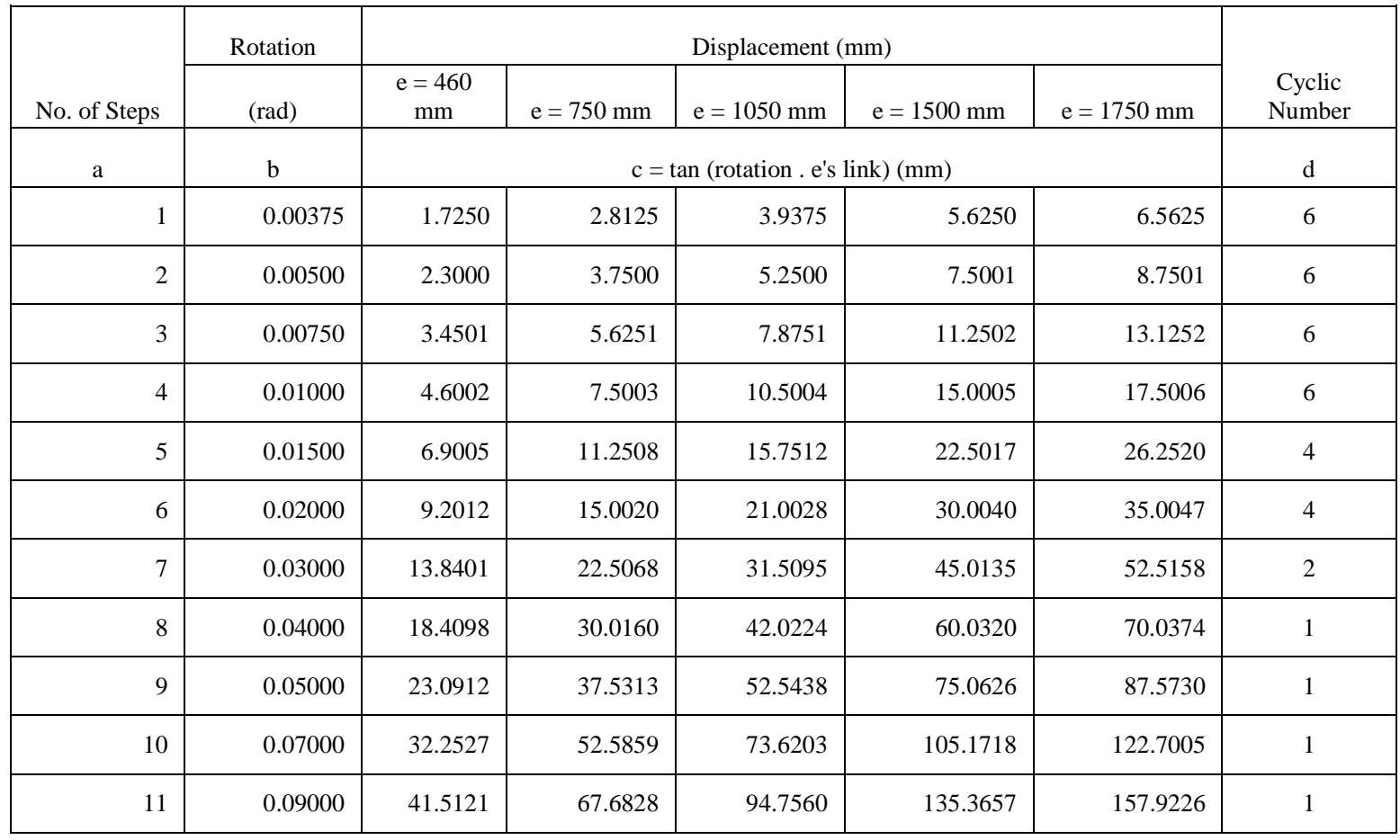


Modeling in this research used a non-linear model, with cyclic loading. Each model was fixed in its one end, then was given a displacement control load in another end, as seen in Figure 1 below.

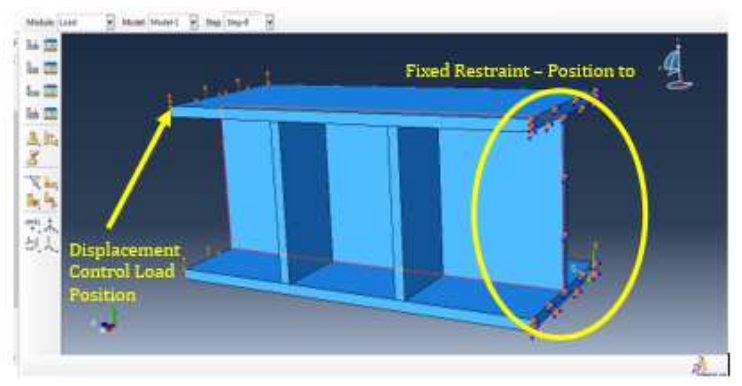

Fig. 1 Link model was fixed in its one end and was given a displacement control load in another end

\section{RESULT AND DISCUSSION}

\section{A. Short Link}

The used data are the displacement data of $\mathrm{Y}$-axis direction, along with shear force that works on the Y-axis. In cantilever beam, the maximum shear force was located in the fixed end of the beam.

Next, the used RF2 and U2 data were combined so that it becomes a related curve. Where rotation angle is used as the $\mathrm{x}$-axis and shear force is on the $\mathrm{y}$-axis. As seen in Hysteresis curve of the short link in Figure 2.

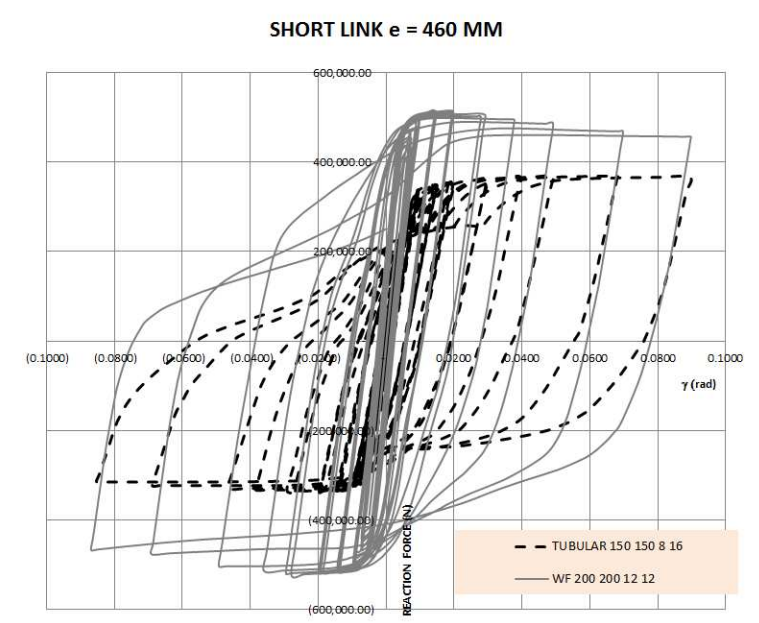

Fig. 2 Hysteretic Curves of Short Link

Others thing to be calculated are analytical nominal shear force using an equation in SNI 1729-2002 [3], as follows:

- For the Tubular link:

$$
\begin{aligned}
& V p=0.6 \mathrm{fy} \text { Aw } \\
& \begin{aligned}
V p_{t u b} & =0.6 .345 .(8 \times(150-2 \times 16)) 2 \\
& =390816 \mathrm{~N} \\
& =390 \mathrm{kN}
\end{aligned} \\
& \begin{aligned}
M p_{T U B} & =Z x F y \\
& =377296 \mathrm{~mm}^{3} \times 345 \mathrm{MPa} \\
& =130167120 \mathrm{Nmm} \\
e & =460 \mathrm{~mm} \\
2 \mathrm{Mp} / \mathrm{e} & =2.130167120 \mathrm{Nmm} / 460 \mathrm{~mm}
\end{aligned}
\end{aligned}
$$

$$
\begin{gathered}
=565944 \mathrm{~N} \\
=566 \mathrm{kN} \\
V n_{T U B} \leq 390 \mathrm{kN} \leq 566 \mathrm{kN} \\
V n_{T U B} \quad=390 \mathrm{kN}(\text { from Figure 2) }
\end{gathered}
$$

- For WF link:

$$
\begin{aligned}
V p_{W F} & =0.6345(12 \times(200-2 \times 12)) \\
& =437184 \mathrm{~N} \\
& =437 \mathrm{kN} \\
& =460 \mathrm{~mm} \\
M p_{W F} & =Z x F y \\
& =841000 \mathrm{~mm}^{3} \times 345 \mathrm{MPa} \\
& =290145000 \mathrm{Nmm} \\
2 M p / e & =2.290145000 \mathrm{Nmm} / 460 \mathrm{~mm} \\
& =1261500 \mathrm{~N} \\
& =1261 \mathrm{kN} \\
V n_{W F} \leq 437 \mathrm{kN} & \leq 1261 \mathrm{kN} \\
V n_{W F} & =437 \mathrm{kN}(\text { from Figure 2) }
\end{aligned}
$$

From the following calculation, shear value from hysteresis curves was same with nominal shear from the calculation. This cases happened because the link was in stable condition.

Graphically, the stress and strain curves can be seen in Figure 3. From that graph, the ductility data can be calculated. The calculation could be done by dividing the last step strain with the value of strain when start yielding, as seen below:

$$
\begin{aligned}
\text { Tubular Ductility } & =\varepsilon \mathrm{u}_{t u b} / \varepsilon \mathrm{y}_{\mathrm{tub}} \\
& =0.0757 / 0.0046 \\
& =16.569 \\
& =\varepsilon \mathrm{u}_{W F} / \varepsilon \mathrm{y} \mathrm{WF} \\
& =0.0709 / 0.0068 \\
& =10.482
\end{aligned}
$$

In conclusion, the Tubular short link has a better ductility than WF short link. It shows that Tubular short link was more stable resisting the cyclic load.

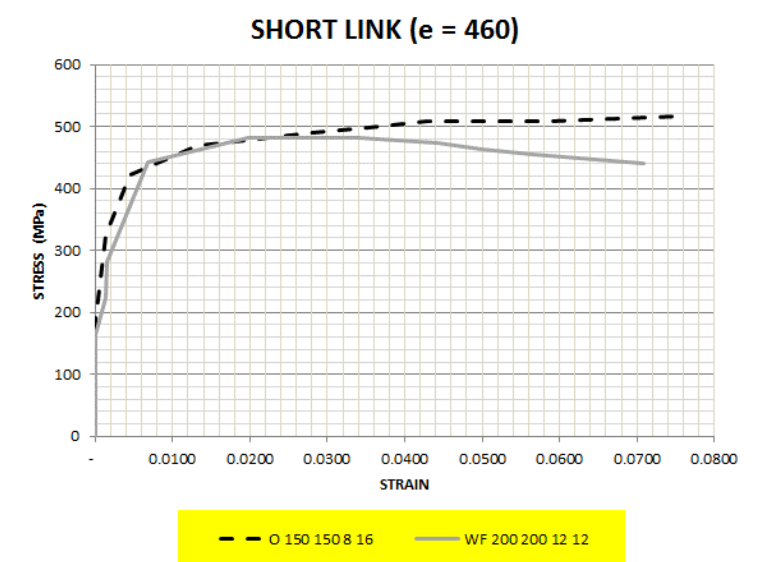

Fig. 3 Stress-Strain Curves of Short Link

\section{B. Long Link}

The data of the long link used the same method as seen in the short link. The used RF2 and U2 data were combined so that it becomes a related curve. Where rotation angle is used 
as the $\mathrm{x}$-axis and shear force is on the y-axis. As seen in Hysteresis curve of the long link in Figure 4.

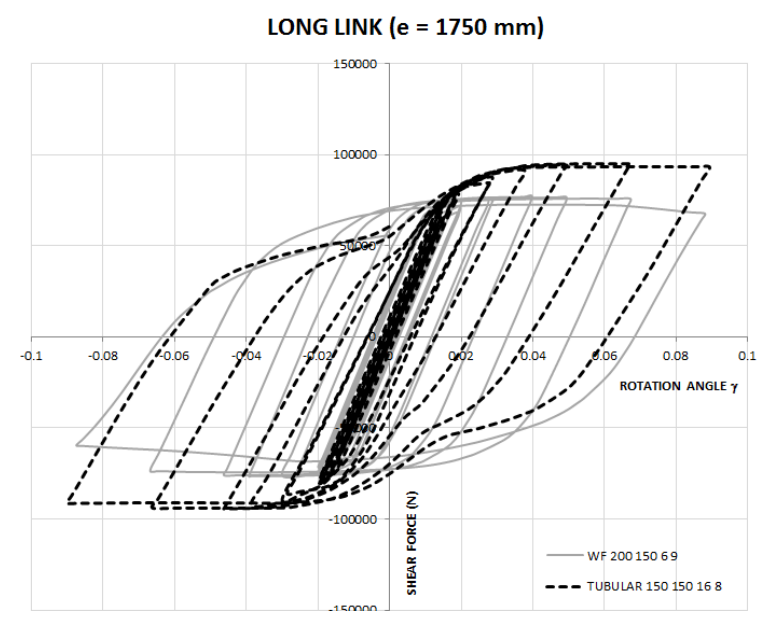

Fig. 4 Hysteretic Curves of Long Link

Others thing to be calculated are a nominal shear force, as follows:

- For the Tubular link:

$V p_{t u b} \quad=390 \mathrm{kN}$ (as in the short link)

$M p_{T U B} \quad=Z x F y$

$=377296 \mathrm{~mm}^{3} \times 345 \mathrm{MPa}$

$=130167120 \mathrm{Nmm}$

e $\quad=1750 \mathrm{~mm}$

$2 \mathrm{Mp} / \mathrm{e} \quad=2.130167120 \mathrm{Nmm} / 1750 \mathrm{~mm}$

$$
=148762.41 \mathrm{~N}
$$$$
=148 \mathrm{kN}
$$

$V n_{T U B} \leq 390 k N \leq 148 k N$

$V n_{T U B} \quad=148 \mathrm{kN}$

- For WF link:

$V p_{W F}$

$=0.6 \mathrm{fy} \mathrm{Aw}$

$=0.6345 \mathrm{MPa}(194 \mathrm{~mm}-2 \times 9 \mathrm{~mm}) 6 \mathrm{~mm}$

$=218592 \mathrm{~N}$

$=219 \mathrm{kN}$

$$
\begin{aligned}
M p_{W F} & =Z x F y \\
& =296000 \mathrm{~mm}^{3} \times 345 \mathrm{MPa} \\
& =102120000 \mathrm{Nmm} \\
& =1750 \mathrm{~mm} \\
2 \mathrm{Mp} / \mathrm{e} & =2.102120000 \mathrm{Nmm} / 1750 \mathrm{~mm} \\
& =116708.57 \mathrm{~N} \\
& =117 \mathrm{Kn}
\end{aligned}
$$

$V n_{W F} \leq 219 k N \leq 117 k N$

$V n_{W F} \quad=117 \mathrm{kN}$

From the analysis in the Figure 4., both Tubular link and WF link have shear forces value that was lower than $\mathrm{Vn}$; it is almost half of the Vn. As an example, in the Tubular link, $\mathrm{Vn}$ from hysteresis curve is found $90 \mathrm{kN}$. Moreover, Vn from calculation was $148 \mathrm{kN}$, the different from hysteresis $\mathrm{Vn}$ is $39,19 \%$. Moreover, WF link had the same trend, Vn from hysteresis curve are found $75 \mathrm{kN}$. Moreover, Vn from calculation was $117 \mathrm{kN}$, the different from hysteresis $\mathrm{Vn}$ is $35,9 \%$.

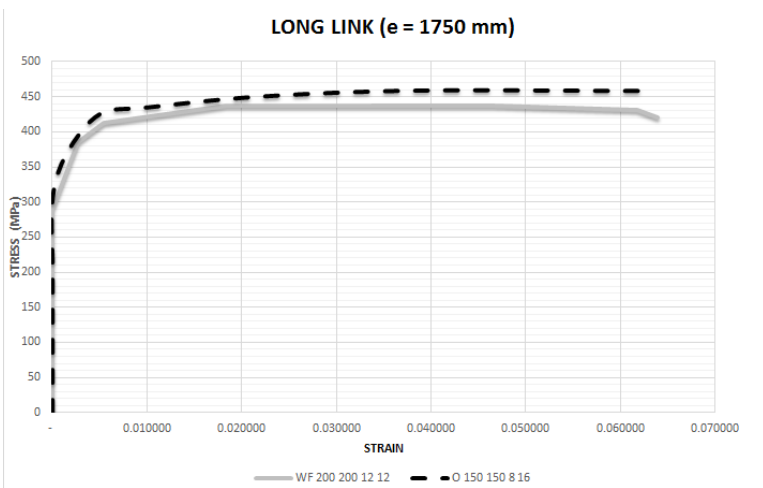

Fig. 5 Stress-Strain Curves of Long Link

Graphically, the stress and strain curves can be seen in Figure 5. From that graph, the ductility data can be calculated. The calculation could be done by dividing the last step strain with the value of strain when start yielding, as seen below:

$$
\begin{aligned}
\text { Tubular Ductility } & =\varepsilon \mathrm{u}_{t u b} / \varepsilon \mathrm{y}_{\text {tub }} \\
& =0.0622 / 0.0050 \\
& =12.400 \\
& =\varepsilon \mathrm{u}_{W F} / \varepsilon \mathrm{y}_{\mathrm{WF}} \\
& =0.0639 / 0.006854 \\
& =11.799
\end{aligned}
$$

In conclusion, the Tubular link has a better ductility than WF link. It shows that tubular link was more stable resisting the cyclic load.

\section{Intermediate Link}

The data of the intermediate link used the same method as seen in the short link and short link. The used RF2 and U2 data were combined so that it becomes a related curve. Where rotation angle is used as the $\mathrm{x}$-axis and shear force is on the y-axis. Hysteresis curve of the intermediate link in Figure 6.

Others thing to be calculated are a nominal shear force, as follows:

- For the Tubular link:

$$
\begin{array}{ll}
V p_{\text {tub }} & =390 \mathrm{kN} \text { (short link) } \\
M p_{\text {TUB }} & =Z x F y \\
& =377296 \mathrm{~mm}^{3} \times 345 \mathrm{MPa} \\
& =130167120 \mathrm{Nmm} \\
e & =1750 \mathrm{~mm} \\
2 \mathrm{Mp} / \mathrm{e} & =2.130167120 \mathrm{Nmm} / 750 \mathrm{~mm} \\
& =347112.30 \mathrm{~N} \\
& =347 \mathrm{kN} \\
V n_{\text {TUB }} \leq 390 \mathrm{kN} & \leq 347 \mathrm{kN} \\
V n_{\text {TUB }} & =347 \mathrm{kN}
\end{array}
$$

- For WF link:

$$
\begin{aligned}
V p_{W F 150200} & =0.6 \mathrm{fy} \mathrm{Aw} \\
& =0.6345 \mathrm{MPa}(194 \mathrm{~mm}-2 \times 9 \mathrm{~mm}) 6 \mathrm{~mm} \\
& =218592 \mathrm{~N} \\
& =219 \mathrm{kN}
\end{aligned}
$$




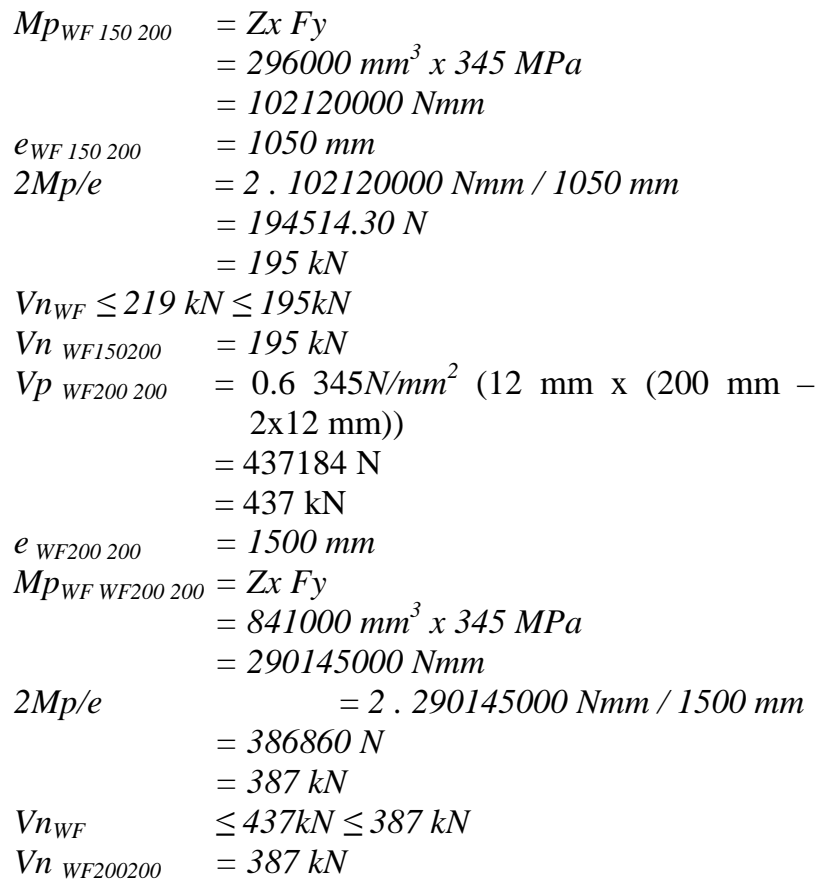

From analysis result in Figure 6, both Tubular wand WF link had a lower hysteresis curves shear force than the analytical calculation of $\mathrm{Vn}$. As an example, Tubular link shear force has $30.84 \%$ different from its nominal shear force analytical calculation, in analytical it was $347 \mathrm{kN}$, and from hysteresis curve, it was $240 \mathrm{kN}$. Moreover, for WF 150 link had the same trend with a Tubular link, in its hysteresis curve the $\mathrm{Vn}$ is $110 \mathrm{kN}$, but from the analytical calculation the value of $V n=194 \mathrm{kN}$, it was $43.45 \%$ ratio.

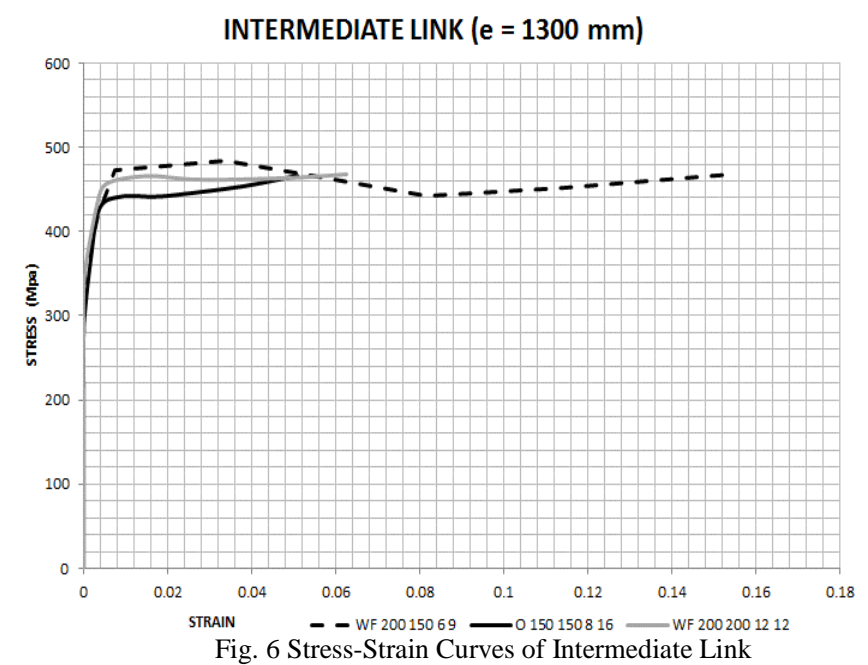

WF 200200 links had a higher ratio, Vn from its hysteretic curve was $150 \mathrm{kN}$, but its analytical load calculation was $V n=387 \mathrm{kN}$, and the different ratio was $61,23 \%$. That might be because WF 200.200 link was chosen because of approximately in the shear link, whereas standard link classification that was taken was approximate to long link with ratio $M p / V p=2.25$.

It shows that Tubular link works more optimal indue to cyclic loading, as seen in its ratio that is less than other WF link. WF link specimen could not reach plastic shear due to reducing stiffness because of lateral buckling.

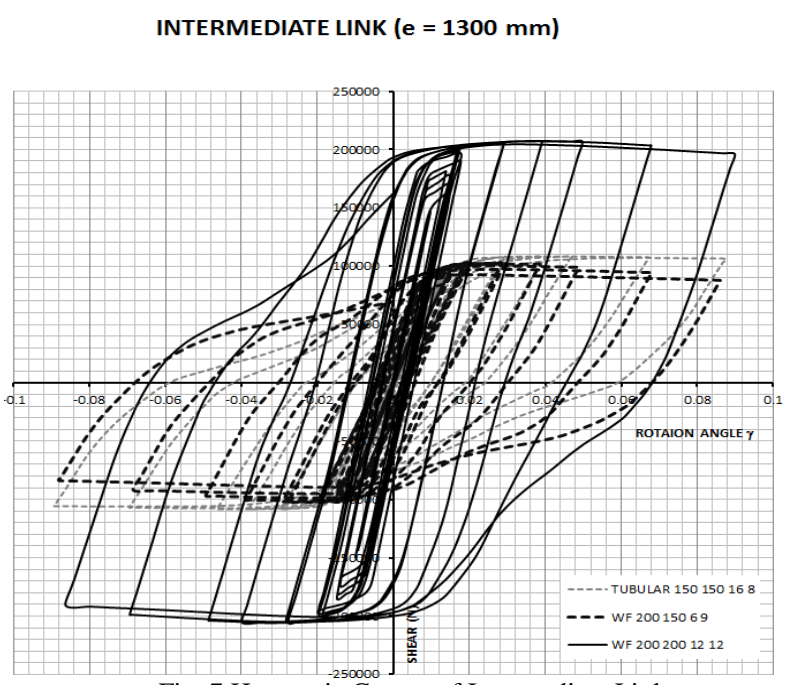

Fig. 7 Hysteretic Curves of Intermediate Link

Graphically, the stress and strain curves can be seen in Figure 7. From that graph, the ductility data can be calculated. The calculation could be done by dividing the last step strain with the value of strain when start yielding, as seen below:

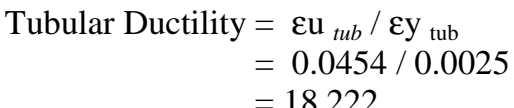

$\begin{aligned} \text { WF 200.150 Ductility } & =\varepsilon u_{W F} / \varepsilon y_{W F} \\ & =0.1475 / 0.0055 \\ & =27.066 \\ & \\ \text { WF 200.200 Ductility } & =\varepsilon u_{W F} / \varepsilon y_{W F} \\ & =0.715 / 0.0051 \\ & =14.145\end{aligned}$

In conclusion, the Tubular link has a better ductility than WF link with the same area. However, the Tubular link has less ductility than WF link with the same inertia. On the other side, found that WF 200.150 link had decline trend when cyclic load value added, different with a tubular link that was more stable resisting the cyclic load. It shows that Tubular link stiffness is better than WF link.

\section{CONCLUSIONS}

The following results can be concluded from the comparison between WF links and tubular links analyzed using the finite element analysis (FEA) aids program. On the Short Links, both WF links and tubular links, the shear force values that occur due to cyclic loads reach a nominal shear force value whose value is equivalent to the $\mathrm{Vp}$, plastic shear force of cross-sectional shear force. The nominal shear force value achieved in the experimental results approximates the manual calculation of the plastic shear force Vp. For tubular $\mathrm{Vp}$ reaches $390 \mathrm{kN}$, while Vp WF reaches $437 \mathrm{kN}$. 
Short-classified links achieve shear forces whose values are highly dependent on the cross-sectional area of the body, so that the WF cross-section may achieve a higher shearing force than the tubular link. With an $89 \%$ body area of the WF body area, the tubular link also achieves an $89 \%$ shear value of the WF link shear force.

The larger rotation angle given on the short link, the shear force values that occur in the WF link decreases (from step 8 to step 11 down by $2.75 \%$ of average per step), this is due to local buckling that occurs on WF links. Meanwhile, the shear force values in tubular links are more stable when there is the addition of cyclic rotation angle.

On the Long links, neither WF links nor tubular links could not achieve the nominal shear force shear value. The tubular link only achieves a value of $\mathrm{V}$ about $61.81 \%$ of its nominal shear force value, whereas the WF link reaches $64.10 \%$ of its nominal shear value.

The larger rotation angle is given in the Long Link, the shear force value that occurs in the WF link decreases, this is caused by lateral buckling that occurs in the WF link. Meanwhile, the shear force values in tubular links are more stable when there is the addition of cyclic rotation angle.

On the Intermediate links, both WF links and tubular links, the achieved shear force could not reach nominal shear force shear value. The tubular link only reaches $\mathrm{V}$ value $69.16 \%$ of its nominal shear force value, whereas the WF 200.150 link reaches $57.55 \%$ of the nominal shear value, and the WF 200. 200 link reaches only about $38.77 \%$ of the crossed Vn value.

The larger the rotation angle given in the Intermediate Link, the shear force value that occurs in the WF link decreases, this is caused by lateral buckling that occurs in the WF link. Meanwhile, the shear force values in tubular links are more stable when there is the addition of cyclic rotation angle.

\section{ACKNOWLEDGMENT}

Authors wishing to acknowledge assistance or encouragement from colleagues, technical staff and especially for Civil Engineering Department, LPPM ITS, and Institut Teknologi Sepuluh Nopember.

\section{REFERENCES}

[1] American Institute of Steel Construction. "AISC Seismic Provision," Chicago: AISC, 2010.

[2] B. Suswanto, AR Amalia, E. Wahyuni "Numerical Behavior Study Of Short Link, Intermediate Link And Long Link In Eccentrically Braced Frame Steel Structure," International Journal of Applied Engineering Research ISSN 0973-4562 Volume 12, Number 21 (2017) pp. 11460-11471

[3] Badan Standardisasi Nasional. "SNI 03 -1729 2002 Tata Cara Perencaaan Struktur Baja Untuk Bangunan Gedung. Departemen Pekerjaan Umum," 2010.

[4] Budiono, Bambang, Yurisman, Nidiasari. (2011), "Perilaku Link Panjang dengan Pengaku Diagonal Badan pada Sistem Struktur Rangka Baja Tajan Gempa". Seminar dan Pameran HAKI. Jakarta.

[5] Daneshmand, Ardeshir, dan Behrokh H. Hashemi. (2011), "Performance of Intermediate and Long Links in Eccentrically Braced Frames." Journal of Constructional Steel Research, 70 (11): 167-176.

[6] Hashemi, Seyed H. (2011), "Ductility and Ultimate Strength of Eccentric Braced Frame.” Proceeding of International Conference on Advanced Materials Engineering, Cairo, Mesir, 1-3 October.

[7] JW Berman and M Bruneau, "Experimental and analytica investigation of tubular links for eccentrically braced frames." Science Direct - Engineering Structure, 2006

[8] JW Berman and M Bruneau, "Development of Self-Stabilizing Links for Eccentrically Braced Frames." Structure Congress - New Horizons and Better Practice, 2007.

[9] Musmar, M.A. 2012. "Effect of Link on Eccentrically Braced Frames.” Journal of Engineering Sciences, Assiut Universiy. Vol 40, 1 (1): 35-43.

[10] T. Okazaki, "Cyclic loading behavior of EBF links constructed of ASTM A992 steel". Science Direct - Engineering Structure, 2006.

[11] Ricles, James M., dan Egor P. Popov. (1994), "Inelastic Link Element for EBF Seismic Analysis." Journal of Structural Engineering, 120 (2): 441-463.

[12] Ricles, James M., dan Egor P. Popov. (1994), "Inelastic Link Element for EBF Seismic Analysis." Journal of Structural Engineering, 120 (2): 441-463.

[13] Richards, Paul W., dan Chia-Ming Uang. (2005), "Effect of Flange Width-Thickness Ratio on Eccentrically Braced Frames Link Cyclic Rotation Capacity." Journal of Structural Engineering, 131 (10): 1546-1552.

[14] Yurisman, et al. (2010), "Behavior of Shear Link of WF Section with Diagonal Web Stiffener of Eccentrically Braced Frame (EBF) of Steel Structure.” Journal of Engineering Sciences, 2 (7): 103-128. Institut Teknologi Bandung, Bandung 